\title{
Study of Nontuberculous Mycobacteria Isolated from the Theater Environment
}

\author{
Seung-Gu Choi ${ }^{1}$, Woon-Heung Song ${ }^{1}$, Dae-Jeung Kim ${ }^{2}$ and Jae-Sang Lee ${ }^{3}$ \\ ${ }^{1}$ Department of Biomedical Laboratory Science, Shin Han University, Uijeongbu 480-701, Korea \\ ${ }^{2}$ Department of Laboratory Medicine, Bundang Jesaeng general hospital, Seongnam 463-774, Korea \\ ${ }^{3}$ Dongam Medical Institute, Goyang 412-814, Korea
}

\begin{abstract}
The nontuberculous mycobacteria (NTM) have been found in different environmental sources. They tend to colonize different body surfaces and secretions. The purpose of this study is to evaluate the presence of NTM in the theater environment. Fifty of Theater environment sample were examined using acid-fast stain, Lowenstein -Jensen medium culture, PCR and DNA-Sequencing. 4 of 50 samples were detected as NFB in AFB stain, L-J medium culture, PCR. and then, All of 4 NTM stains identified as Mycobacterium fortitum type in DNA-sequencing result.
\end{abstract}

Keywords: Nontuberculous mycobacteria (NTM), Theater environment, DNA sequencing

This is an Open Access article distributed under the terms of the Creative Commons Attribution Non-Commercial Licens (http://creativecommons.org/licenses/by-nc/3.0) which permits unrestricted non-commercial use, distribution, and reproduction in any medium, provided the original work is properly cited.

Copyright (C) 2015 The Korean Society for Clinical Laboratory Science. All rights reserved.
Corresponding author: Seung-Gu Choi Department of Biomedical Laboratory Science, Shin Han University, Uijeongbu 480-701, Korea

Tel: 82-31-870-3404

E-mail: sgchoi3236@hanmail.net

Received: March 19, 2015

Revised: March 23, 2015

Accepted: March 24, 2015

\section{Introduction}

Nontuberculous mycobacteria (NTM) has been called as atypical mycobacteria mycobacteria other than tuberculosis (MOTT) from the past, and studies on contaminants distributed naturally in the natural environments such as soils and river streams have been carried out. The observation results have proven that NTM is not only distributed in the natural environments, but also it exists in water supply facilities and other various environments adjacent to human beings, causing various diseases to human beings.

Therefore, the risk of NTM as pathogen has come into the spotlight again.

Since 1980s, cases of tuberculous infections in patients with immune deficiency such as acquired immune deficiency syndrome (AIDS) have increased in U.S., Europe and Japan as well as cases of lung diseases in adults with normal immune status due to NTM also have increased gradually (Falkinham, 1996). Various experiments and clinical cases have proven that NTM separated from the tap water in hospitals causes lung diseases in patients with immune deficiency and furthermore some NTM species are being detected from mineral water available in the market and natural environments (Caroli et al., 1985; Hillebrand- Haver-kort et al., 1999).

Since NTM has been detected from tap water and natural environments (Covert et al., 1999; Argueta et al., 2000; Chang et al., 2002), it is possible to assume that NTM may exist in multi-use facilities where many people use, and if this assumption is proven, it is highly possible that multi-use facilities may also become environments which could cause lung diseases to people with immune deficiency.

Upon the consideration that if NTM was detected from multi-use facilities where the general public could use and access frequently, it could affect the public health significantly and cause various serious social and sanitary problems, it was decided to carry out a study regarding the existence of NTM in multi-use facilities, and clinical specimens were collected and examined from 50 multi-use facilities in the capital area, and in order to detect NTM, acid-fast staining 
and Löwenstein-Jensen (L-J) medium inoculation were carried out. And, the PCR method was carried out on cultured bacterial species. Sequencing and separation of bacterial species were performed and NTM contamination level and contaminant bacterial species in the theater environment were identified.

\section{Materials and Methods}

For the samples in this study, clinical specimens (dust) were collected from places that could affect the general public most closely such as seats and floor handles in 50 theaters of multi-use facilities in the capital area using sterilized cotton swabs, and sterilized distilled water was added to the collected clinical specimens and the process of centrifugation was carried out for 30 minutes at 2000 RPM. Supernatant was removed, precipitate was treated with $4 \% \mathrm{NaOH}$ for 20 minutes, Acid-fast staining which was the Kinyoun method and L-J medium inoculation were carried out (Difco, USA), and direct PCR analysis was performed (Koneman et al., 1997).

For the L-J medium method, the inoculation was carried out with a sterilized loop for 8 -week culture at $37^{\circ} \mathrm{C}$, acid-fast staining was carried out and indirect PCR was applied. For direct PCR method, sterilized distilled water was added to the collected clinical specimens, the process of centrifugation was carried out for 30 minutes at 2000 RPM, supernatant was removed and precipitate was let floating on TE Buffer $1 \mathrm{~mL}$. (Zwadyk et al., 1994) For indirect PCR method, a cluster cultured on L-J medium was inserted to TE Buffer $1 \mathrm{~mL}$ using the sterilized loop, the centrifugation was carried out for 5 minutes at 13000 RPM, supernatant was removed, precipitate was mixed with DNA extract $200 \mu \mathrm{L}$, and it was heated for 20 minutes at $100^{\circ} \mathrm{C}$ after vortex mix for 30 seconds in order to extract DNA. Centrifugation was carried out for 5 minute at 13,000 RPM and $3 \mu \mathrm{L}$ was collected from supernatant liquid and used for PCR.

For PCR reaction solution, $20 \mu \mathrm{L}$ reaction solution was created and used on the experiment by adding extracted DNA $3 \mu \mathrm{L}, 5 \times$ MTB/NTM ACE PM $4 \mu \mathrm{L}$, 8-MOP solution $3 \mu \mathrm{L}$, $2 \times$ Multiplex Master $10 \mu \mathrm{L}$ to PCR premix (Bioneer, Korea).
For the reaction condition of thermal cycler, the reaction was carried out at $94^{\circ} \mathrm{C}$ for 15 minutes, and a total of 42 cycles were carried out for 10 minutes at $72^{\circ} \mathrm{C}$ after the degeneration reaction (for 30 seconds at $94^{\circ} \mathrm{C}$ ), coupling reaction (for 30 seconds at $62^{\circ} \mathrm{C}$ ), elongation reaction (for 30 seconds at $72^{\circ} \mathrm{C}$ ). For checking the PCR result, $5 \mu \mathrm{L}$ Etidium bromide was added to $2 \%$ agarose gel and DNA was stained. Electrophoresis of DNA size marker and PCR reaction product $3 \mu \mathrm{L}$ was carried out at 100 volt for 20 minutes and the reaction product was checked in UV transilluminator. (Telenti et al., 1993).

For clinical specimens proven to be atypical tuberculosis bacillus in PCR result, DNA-sequencing was carried out and Mycobacterium species were separated and identified (MTB/ NTM ACE V3.0, Seegene).

\section{Results}

In order to confirm, prove the existence of NTM in multi-use facilities and analyze its influence, samples from 50 multi-use facilities (theaters) in the capital area were collected and tested in this study, and the result of acid-fast staining and culture using L-J medium showed that 4 out of 50 samples have tested positive, showing a $8 \%$ positive rate (Fig. 1). The result of direct PCR on enriched samples showed that all 50 samples have tested negative. For culture using L-J medium, clusters were formed in 4 samples (8\%), and in order to confirm the existence of NTM, each cluster was collected using a sterilized loop, and acid-fast staining and indirect PCR were carried out.

As a result of Acid-fast staining, 4 out of 4 samples tested positive and these samples also tested positive in indirect PCR result (Fig. 2). For the result of samples tested positive, it was confirmed through the sequencing and separation of bacterial species that all the samples tested positive were Mycobacterium fortuitum type (Fig. 3).

\section{Discussion}

NTM infects AIDS patients as well as patients with immune deficiency, causing tuberculous infection (Falkinham, 1996). Previously, NTM has been recognized as a pathogen-free 


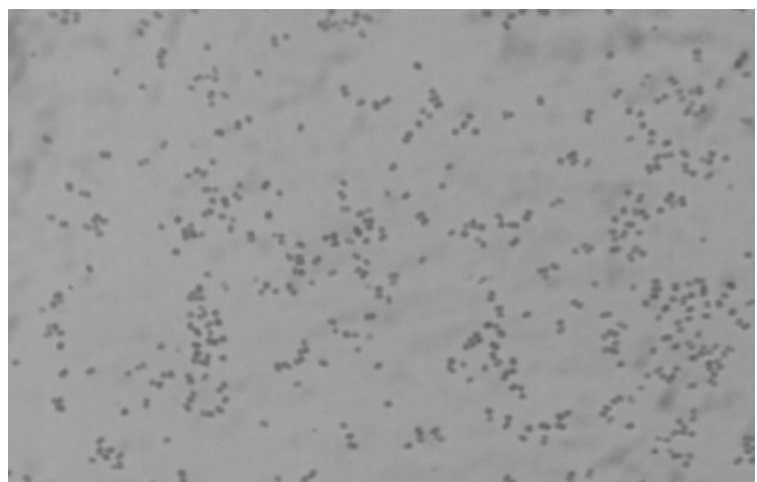

(A)

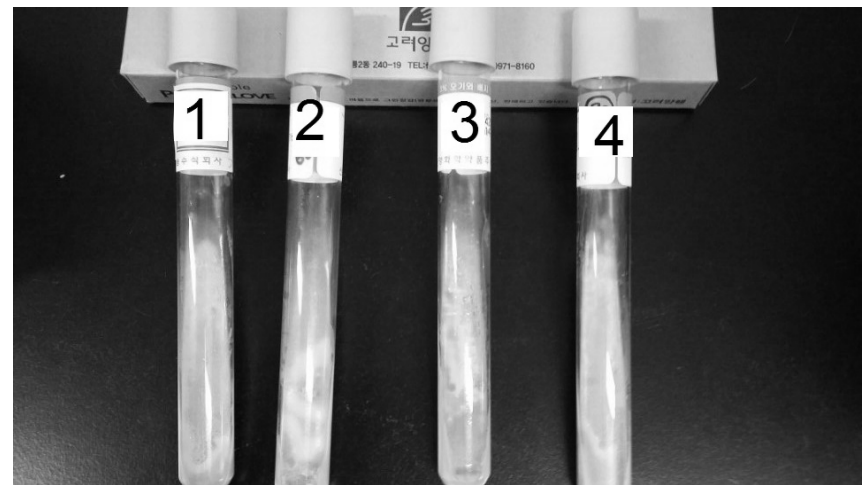

(B)

Fig. 1. (A) Smear of NTM prepared from LJ culture medium stained with Ziehl-Neelsen stain. (B) Growth of NTM on LJ agar slant after 5 days of incubation at $37^{\circ} \mathrm{C}$.
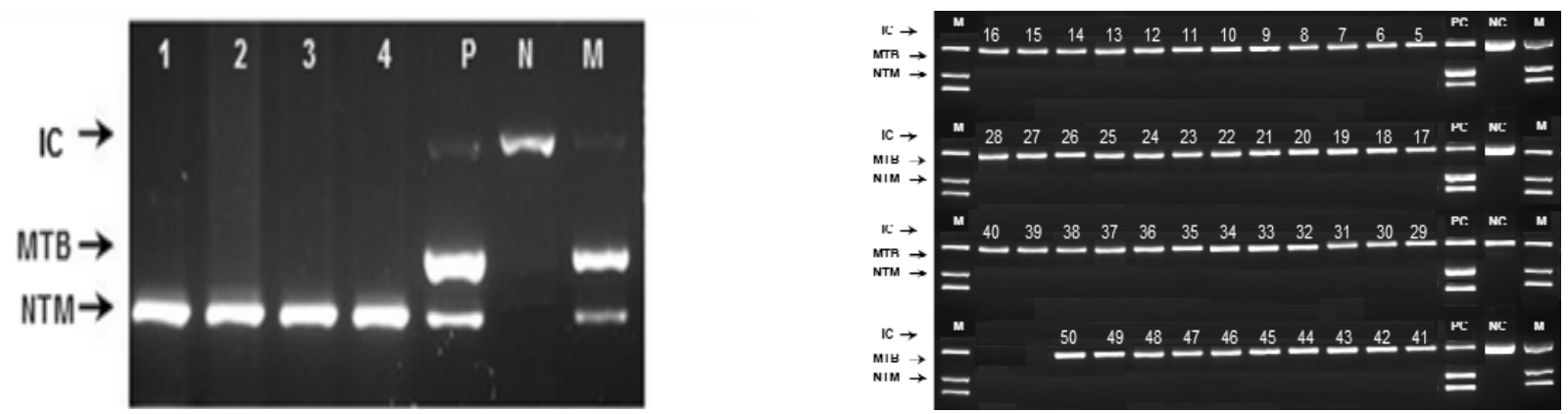

Fig. 2. Gel electropheresis of the NTM and NTB PCR. Lanes: M, molecular marker; P, positive; N, negative; 1 4, NTM positive samples; 5 50, NTM negative samples.

\begin{tabular}{|c|l|r|r|r|r|r|r|}
\hline NAME & \multicolumn{1}{|c|}{ Description } & Max score & Total score & Query cover & E value & Max ident & Accession \\
\hline 1 & $\begin{array}{l}\text { Mycobacterium fortuitum strain AFP-000SM8 16S ribosomal RNA } \\
\text { gene, partial sequence }\end{array}$ & 2372 & 2372 & $100 \%$ & 0 & $99 \%$ JX266697.1 \\
\hline 2 & $\begin{array}{l}\text { Mycobacterium fortuitum strain AFP-000SM8 16S ribosomal RNA } \\
\text { gene, partial sequence }\end{array}$ & 2512 & 2512 & $100 \%$ & 0 & $100 \%$ ]X266697.1 \\
\hline 3 & $\begin{array}{l}\text { Mycobacterium fortuitum strain AFP-000SM8 16S ribosomal RNA } \\
\text { gene, partial sequence }\end{array}$ & 2254 & 2254 & $100 \%$ & 0 & $99 \%$ ]X266697.1 \\
\hline 4 & $\begin{array}{l}\text { Mycobacterium fortuitum strain AFP-000SM8 16S ribosomal RNA } \\
\text { gene, partial sequence }\end{array}$ & 2063 & 2063 & $100 \%$ & 0 & $100 \%$ ]X266697.1 \\
\hline
\end{tabular}

Fig. 3. Sequencing result for confirming NTM species.

strain which is harmless to people. However, many recent studies have proven that NTM exists in anywhere with human life and it is a strain which causes serious lung diseases through the respiratory system of people with weak immunogenicity and it may also infect people with normal immunogenicity, causing diseases (Falkinham, 1996; Chang et al., 2002). Therefore, it was decided to investigate whether NTM existed in theaters which were used by the general 
public or not based on the contents mentioned above, and dust samples were collected from 50 theaters in the capital area for the experiment and confirmation. And then, AFB staining, culture on L-J medium, PCR and Sequencing were used, and rbsthralc rbs was separated and identified.

In other experiment results regarding NTM in multi-use facilities, Chang et al. (2002) obtained the detection rate of 20.4\% from tap water and Covert et al. (1999) obtained the detection rate of $54 \%$ from ice samples and NTM detection rate of $35 \%$ from drinking water available in the market. Argueta et al. (2000) obtained the result that 25 out of 121 food samples have tested NTM positive, showing the detection rate of $20.6 \%$. And, Choi et al. obtained NTM detection rate of $6.25 \%$ from tap water samples. Meanwhile, NTM detection rate from dust samples collected from theaters in this study was $8 \%(4 / 50)$. This result was somewhat lower than $20.4 \%$ obtained by Chang et al, $54 \%$ from ice samples and $35 \%$ from drinking water obtained by Covert et al, and 20.6\% obtained by Argueta et al. However, it was similar with 6.25\% obtained by Choi et al. Such difference in the detection rate between countries and areas is caused by various environmental differences or environmental factors, indicating that these differences and factors should be considered. However, in order to block the spread chain of disease, it is important to carry out continuous and systematic monitoring in public areas and build and update DB with monitoring data.

The fact in this study that NTM was detected from theaters which are public areas is very significant that the environment which may cause lung diseases to either people with immune deficiency or people with normal immune system was established.

The result showing that NTM existed in living environments of multi-use facilities corresponded to the result of other previous studies. It is generally known that NTM contamination in natural environments could be the source of tubercular infection for patients with immune deficiency and it is pointed out as a public health problem. Therefore, it is very important to classify and identify NTM into bacterial species in the epidemiologic investigation.

It has been proven that $M$. avium is an important strain which causes tuberculosis-related diseases in patients with immune deficiency (Falkinham, 1996). It was reported that nosocomial outbreaks occurred by NTM were related to contaminated natural environments (Wallace et al., 1998). In addition, some bacterial species such as M. avium and M. szulgai have been identified from the surface of cooling water and spray water samples in dental hospital. M.fortuitum may be detected from nature, sewage and dust, and direct and indirection infection from contaminated tap water are also possible, so in order to prevent relevant diseases, it is necessary to investigate surrounding natural environments as well as other living environments (Schulze-Röbbecke et al., 1995).

In the result of this study, NTM was detected from 4 out of 50 samples from theaters in multi-use facilities and the sequencing result showed that all 4 NTM were identified as M.fortuitum. This result was similar with the result of other studies mentioned above (Choi et al., 2013).

This result of this study has proven that theaters in multi-use facilities are contaminated with NTM (M.fortuitum), and it is significant as material which could prove the spreading path of pathogenic microorganism to human beings through natural environments and other environmental factors.

Theaters in multi-use facilities are public places used by unspecified individuals regardless of individual variation in the level of immunity, so thorough environmental management and collective efforts are necessary to create these places more healthy.

\section{Acknowledgements: None \\ Funding: None \\ Conflict of interest: None}

\section{References}

1. Argueta C, Yoder S, Holtzman AE, Aronson TW, Glover N, Berlin OG, Stelma GN Jr, Froman S, Tomasek P. Isolation and identification of nontuberculous mycobacteria from foods as possible exposure sources. J Food Prot. 2000, 63:930-933.

2. Böddinghaus B, Rogall T, Flohr T, Blöcker H, Böttger EC. Detection and identification of mycobacteria by amplification of rRNA. J Vlin Microbiol. 1990, 28:1751-1759. 
3. Caroli G, Levre' E, Armani G, Biffi-Gentili S, Molinari G. Search for acid-fast bacilli in bottled mineral waters. J Appl Bacteriol. 1985, 58:461-463.

4. Chang CT, Wang LY, Liao CY, Huang SP. Identification of nontuberculous mycobacteria existing in tap water by PCR-restriction fragment length polymorphism. Appl Environ Microbiol. 2002, 68:3159-3161.

5. Covert TC, Rodgers MR, Reyes AL, Stelma GN Jr. Occurrence of nontuberculous mycobacteria in environmental samples. Appl Environ Microbiol. 1999, 65:2492-2496.

6. Falkinham JO 3rd. Epidemiology of infection by nontuberculous mycobacteria. Clin Microbiol Rev. 1996, 9:177-215.

7. Hillebrand-Haverkort ME, Kolk AH, Kox LF, Ten Velden JJ, Ten Veen JH. Generalized Mycobacterium genavense infection in HIV-infected patients: detection of the mycobacterium in hospital tap water. Scand J infect Dis. 1999, 31:63-68.

8. Kim BJ, Lee SH, Lyu MA, Kim SJ, Bai GH, chae GT, Kim EC, Cha CY, Kook YH. Identification of mycobacterial species by comparative sequence analysis of the RNA polymerase gene (rpoB). J Clin Microbiol. 1999, 37:1714-1720.

9. Koneman EW, Allen SD, Janda WM, Schrecken-berger PC, Winn Jr. WC (ed.). Color atlas and textbook of diagnostic microbiology. 5th ed. 1997, P893-952, Lippincott Williams \&
Wilkins, NY.

10. Schulze-Röbbecke R, Feldmann C, Fischeder R, Janning B, Exner M, Wahl G. Dental units: an environmental study of sources of potentially pathogenic mycobacteria. Tuber Lung Dis. 1995, 76:318-323.

11. Telenti A, Marchesi F, Balz M, Bally F, Bottger EC, Bodmer T. Rapid identification of mycobacteria to the species level by polymerase chain reaction and restriction enzyme analysis. $J$ Clin Microbiol. 1993, 31:175-178.

12. Wallace RJ Jr. Brown BA, Griffith DE. Nosocomial outbreaks/ pseudo-outbreaks caused by nontuberculous mycobacteria. Annu Rev Microbiol. 1998, 52:453-490.

13. Zwadyk P Jr. Down JA, Myers N, Dey MS. Rendering of mycobacteria safe for molecular diagnostic studies and development of a lysis method for strand displacement amplification and PCR. J Clin Microbiol. 1994, 32:2140-2146.

14. Choi seung gu, Song WH, Kang CH, Cho KB, Lee JS Lee JH, Kim SI, Jee SI. Identification of Nontuberculous Mycobacteria Existing in Public Bathrooom Water by PCR-Restriction Fragment Length Polymorphism. Korean J Clin Lab Sci. 2008, 40:1-5.

15. Choi seung gu. Identification of Nontuberculous Mycobacteria Existing in playground sand by PC. 2013, J.Shihheung college. 